(continued from previous page)

same levels of light brown apple moth control as obtained in New Zealand. Many fruit crops in California already receive control measures for native and introduced leafrollers, and these tactics may prove to be effective for light brown apple moth without a great deal of modification.

If the New Zealand experience is any indication, adequate control of this leafroller can be achieved more effectively through a vigorous program of biological control and the use of selective insecticides for other pest species. That approach identified a need to introduce natural enemies to attack light brown apple moth through all stages of development. The focus on introductions to address parasitism gaps, especially those targeting the late larval and pupal stages, proved to be highly effective. Further exploration of natural enemies in New Zealand may yield guidance for possible parasitoid importations to North America.

As New Zealand has already found, it is unlikely that any one parasitoid will be so specific that it attacks only light brown apple moth. Therefore, any introduction of natural enemies into California must be preceded by a careful cost-benefit analysis. Light brown apple moth is a polyphagous insect, feeding on many plant species, and some native leafrollers may occupy the same niche. The benefit of suppressing populations of light brown apple moth and allowing reduced use of insecticide must outweigh possible adverse impacts on populations of endemic moths and natural enemies. This is an issue that must be carefully considered in the development of a strategic plan for the long-term management of this pest in California.

L.G. Varela is Integrated Pest Management (IPM) Advisor, UC Statewide IPM Program and UC Cooperative Extension; and J.T.S. Walker is Senior Fruit Crop Entomologist, P.L. Lo is Senior Scientist, and D.J. Rogers is Senior Scientist, The New Zealand Institute for Plant \& Food Research Limited, Hawkes Bay, New Zealand.

References (see page 11)

\title{
Airborne particles in the San Joaquin Valley may affect human health
}

by Mai A. Ngo, Kent E. Pinkerton, Sandra Freeland, Michael Geller, Walter Ham, Steven Cliff, Laurie E. Hopkins, Michael J. Kleeman, Urmila P. Kodavanti, Emily Meharg, Laurel Plummer, Julian J. Recendez, Marc B. Schenker, Constantinos Sioutas, Suzette Smiley-Jewell, Christine Haas, Joyce Gutstein and Anthony S. Wexler

\section{Air quality is a primary concern for} many San Joaquin Valley residents. In addition to rapid population growth, a widening interface between urban and agricultural communities, and increasing traffic along the I-5 and Hwy. 99 corridors, farming practices in the San Joaquin Valley subject agricultural workers to high concentrations of airborne particulate matter potentially associated with adverse health effects. We created a research team and mobile field unit equipped with a special inhalation system, particle monitoring and characterization abilities, and housing for the transport and care of animals to examine the effects of particulate matter throughout the San Joaquin Valley. With this system, a variety of biological endpoints can be examined to determine respiratory, systemic and neurological responses to short-term particle exposure. Field research of this nature coupled with biological assays and location-specific inhalation studies can help researchers and regulators to better understand potential health effects due to environmental and occupational airborne-particle exposures faced by workers and residents in the San Joaquin Valley. $\triangle$ griculture is a major industry in in 2007 (CDFA 2009). The state claims nine of the 10 most productive counties in the nation. The majority are in the
San Joaquin Valley, which extends approximately 250 miles from San Joaquin County in the north to Kern County in the south. San Joaquin Valley agriculture encompasses more than 400 plant and animal commodities - with Fresno and Tulare counties leading in agricultural value for the production of grapes, almonds, milk, oranges and cattle. Approximately 4 million people live in the San Joaquin Valley (State of California 2007) and the number of farmworkers is estimated to be between 175,000 to 500,000 .

While the San Joaquin Valley is one of the world's most productive agricultural regions, it is also frequently in violation of U.S. ambient air-quality concentration standards, particularly those for atmospheric particulate matter (PM) (Velasco 2005), which is defined as liquid or solid material such as soil dust or smoke suspended in the air. Particulate levels for the South Coast Air Basin and the Central Valley in California are the highest recorded in the country, exceeding the national ambient air-quality standards for each season of the year. Workers and residents of the San Joaquin Valley are exposed to airborne particulate matter from a broad range of sources including farming practices such as the tilling of dry soil, agricultural burning, crop harvesting and diesel-powered water pumping. Particle emissions include inorganic compounds from soil lofted by, for example, dairy operations and off-road vehicles, or organic matter from animal feed and disturbed, dried manure.

The three parameters - size, composition and distribution - for each classification of particles are sufficiently different that each can produce unique health outcomes following inhalation. Epidemiological studies have shown a strong correlation between the exposure of human populations to particulate matter and acute and chronic health effects, including increased deaths due to cardiovascular illness and emergency room visits related to the severity of asthma symptoms (Sheppard 
et al. 1999; Peters et al. 2000; Pope and Dockery 2006; Pope 2007). Farm and dairy workers and residents of the San Joaquin Valley may be at increased risk for unfavorable health consequences that have been linked to airborne particle exposure.

\section{Health effects of particles}

Particulate matter can be classified by size: coarse, $\mathrm{PM}_{10}$ ( $<10$ microns); fine, $\mathrm{PM}_{2.5}(<2.5$ microns); or ultrafine, $\mathrm{PM}_{0.1}(<0.1$ micron). One micron $(\mu \mathrm{m})$ equals 4 one-hundred-thousandths (0.00004) of an inch. Fine and ultrafine particles, between 0.1 and 2.5 microns, are capable of penetrating deeply into the respiratory tract. Evidence increasingly suggests that these are the more harmful particle sizes because they are associated with increased mortality and respiratory illnesses (Samet et al. 2000; Peters et al. 1997; Englert 2004; Ostro et al. 2006; Pope and Dockery 2006).

Coarse particles, between 2.5 and 10 microns, are also associated with adverse health effects, especially in the elderly, with increased morbidity and mortality due to cardiopulmonary complications (Ostro et al. 2006). Although agricultural activity is generally believed to produce coarse particle emissions $\left(\mathrm{PM}_{2.5}\right.$ to $\left.\mathrm{PM}_{10}\right)$, it also contributes fine $\left(\mathrm{PM}_{2.5}\right)$ and ultrafine $\left(\mathrm{PM}_{0.1}\right)$ particles to the air. For example, diesel emissions from agricultural operations and the burning of agricultural crop waste actively produce $\mathrm{PM}_{2.5}$ and its subset, $\mathrm{PM}_{0.1}$. Moreover, ammonia emitted from fertilizer and livestock can combine with vehicle exhaust to form ammonium nitrate particles in the $\mathrm{PM}_{2.5} / \mathrm{PM}_{0.1}$ range.

$\mathrm{PM}_{10}, \mathrm{PM}_{2.5}$ and $\mathrm{PM}_{0.1}$ particles consist of hundreds of compounds in liquid and solid form created by sources ranging from agricultural activities to diesel engines to vegetative burning (Davidson et al. 2005; Herner et al. 2005). Organic hydrocarbons found in airborne particulate matter such as polycyclic aromatic hydrocarbons and quinones, and transition metals such as chromium and iron, may be responsible for producing reactive oxygen molecules, which induce oxidative stress and subsequent inflammation that can lead to disease (Ghio et al. 1999). Inflammation of the airways following

\section{Workers and residents of the San Joaquin Valley are exposed to a wide range of airborne particulate matter.}

exposure to particulate matter can exacerbate asthma, chronic bronchitis and airway obstruction. Oxidative stress, inflammation or alterations in autonomic (neural control) perturbations from particulate matter exposure may also exacerbate adverse cardiovascular conditions, especially in individuals with pre-existing heart and vascular disease (Ostro et al. 2006; Pope 2007).

\section{PM field studies}

Ambient atmospheric measurements indicate that particulate-matter concentrations in the San Joaquin Valley fluctuate over the course of a day and can vary seasonally and from year to year; variations in weather and emissions are the primary causes of these ambient concentration changes (Chow et al. 1993, 1999; Velasco 2005).

To account for seasonal fluctuations, our initial studies evaluated the health effects of exposure to San Joaquin Valley particulate matter for 2 consecutive weeks in June 2006 (representing summer) and November 2006 (representing winter). The studies utilized a customized, climate-controlled mobile trailer designed specifically for housing laboratory animals and conducting ambient particulate-matter exposure studies.
Young adult rats (10 to 12 weeks of age) were housed and acclimatized for 1 week prior to exposure in our trailer, located at the UC Kearney Agricultural Research Center in the small farming community of Parlier, Calif., approximately 15 miles southeast of Fresno. Animals were housed in standard polycarbonate cages.

During exposure periods, the animals were transferred to cages specifically modified for use as exposure chambers with special sealed tops (Smith et al. 2003). To determine the effects of short-term exposure to particulate matter, the animals were divided into three groups: (1) filtered air (control), (2) fine/ultrafine particles and (3) coarse particles. Animals were exposed 6 hours per day for 3 consecutive days. Ambient air was drawn from the rooftop of the trailer and filtered through HEPA filters for the control animals or concentrated to approximately 20 times ambient levels of fine/ultrafine $\left(\mathrm{PM}_{2.5} / \mathrm{PM}_{0.1}\right)$ or coarse $\left(\mathrm{PM}_{10}\right)$ particles with two different portable Versatile Aerosol Concentrator Enhancement Systems (VACES) (Kim et al. 2001; Smith et al. 2003). All animals were handled according to the U.S. Animal Welfare Act and all procedures

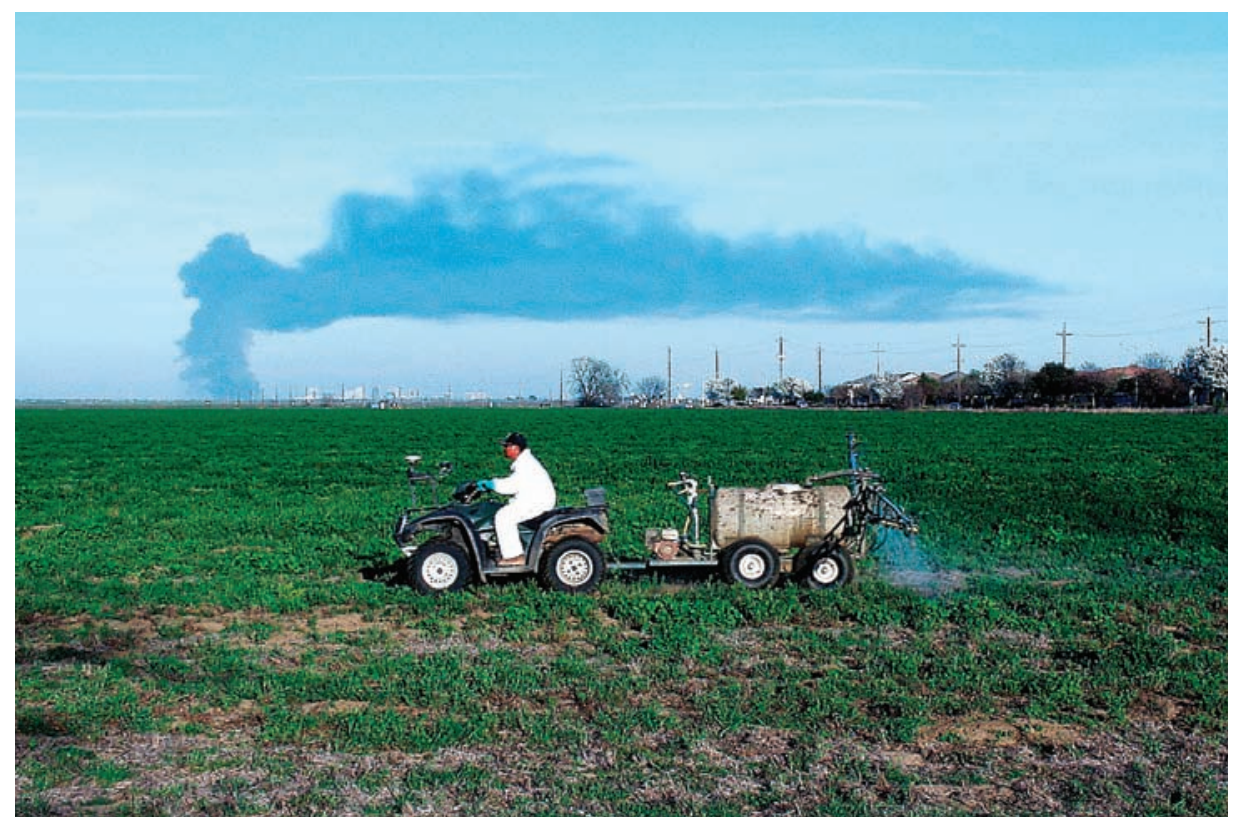

Agricultural workers and residents of the San Joaquin Valley are exposed to airborne pollutants from a broad range of sources. Above, a worker sprays a field during the 2007 railroad bridge fire north of Sacramento. 


\section{Community engagement and outreach}

A critical component of our field studies is translating research to practice, along with community engagement at all levels. Therefore, we participated in a community health fair held in Parlier, titled "Empowering Parlier Community Members to Make Positive Lifestyle Changes - Eat Better and Move More." Sponsored by UC Cooperative Extension in Fresno County, the health fair was attended by more than 200 farmworkers and their families. Participants took full advantage of more than 30 health-awareness booths, which included information about cancer, nutrition and diabetes; free screenings; and hands-on workshops. Through the participation of the Western Center for Agricultural Health and Safety (WCAHS), we sponsored an air-quality booth with bilingual handouts, interactive materials and graphics for nonreaders, created for the event. The San Joaquin Valley Unified Air Pollution Control District, the California Air Resources Board and the Fresno-Madera Medical Society also provided air-quality brochures.

Keynote speaker California Assembly Member Juan Arambula (31st district) and Parlier City Manager Lou Martinez acknowledged the contributions of the health fair to their communities and noted that the collaboration of health care workers, researchers, government agencies and volunteers is making significant progress in raising health awareness and facilitating realistic approaches that promote positive lifestyle changes.

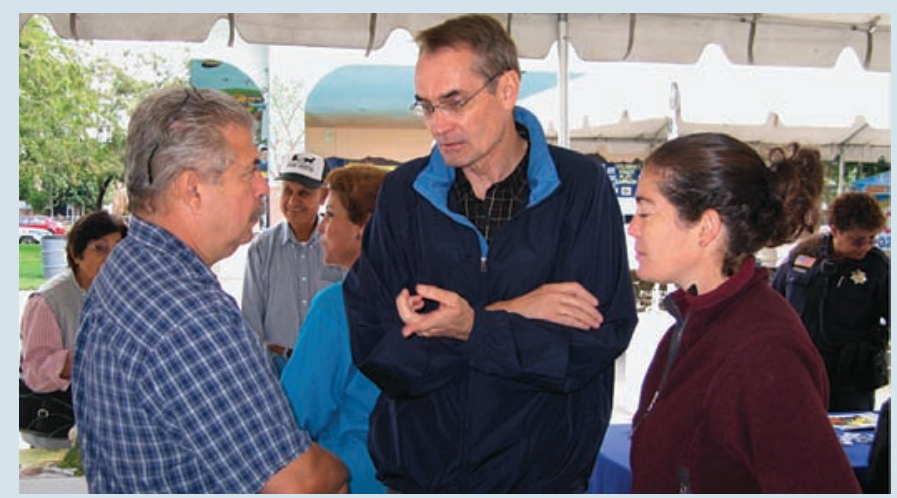

At a health fair in Parlier, Assemblyman Juan Arambula (left) discusses air quality with Kent Pinkerton and graduate student Emily Meharg of the Western Center for Agricultural Health and Safety at UC Davis.

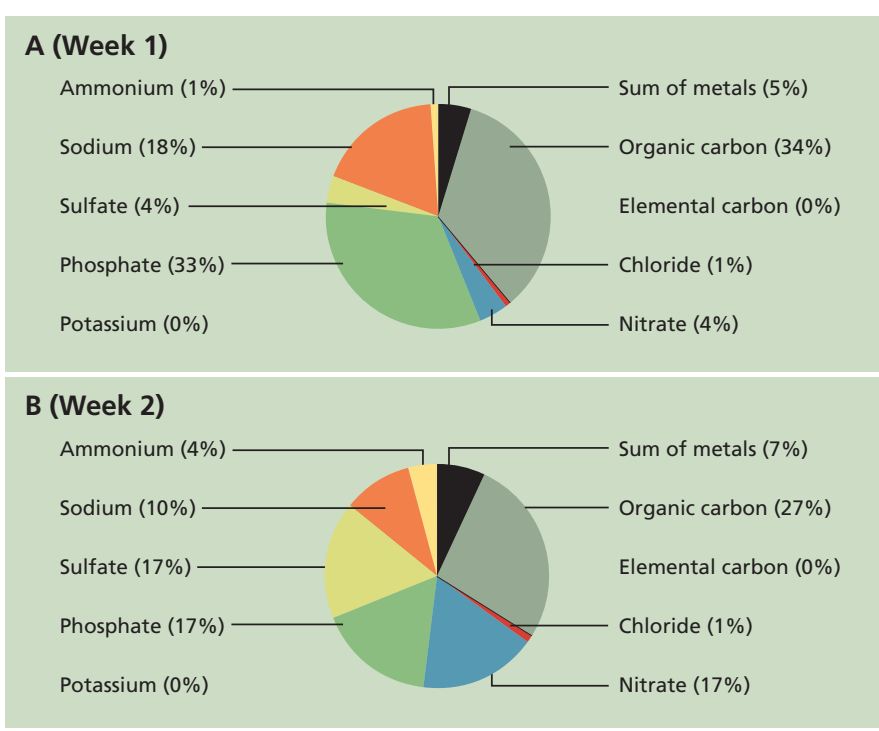

Fig. 1. Chemical composition of fine/ultrafine particles measured during 3-day particle exposure in the San Joaquin Valley, June 2006.

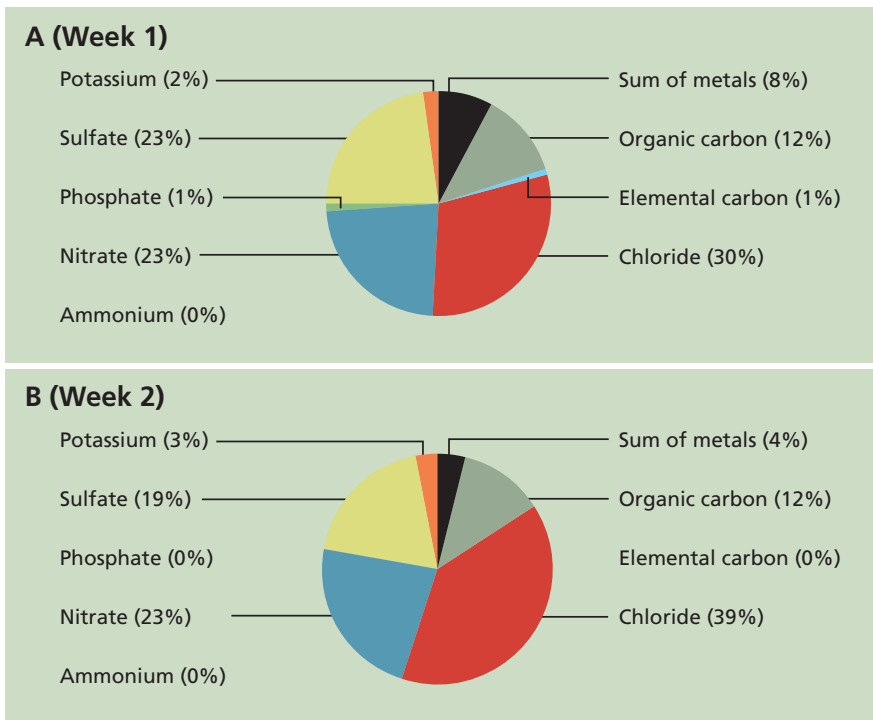

Fig. 2. Chemical composition of coarse particles measured during 3-day particle exposure in the San Joaquin Valley, June 2006. were performed under the supervision of the University Animal Care and Use Committee at UC Davis.

To determine ambient particlemass concentrations for ultrafine, fine and coarse particles, as well as their

TABLE 1. Particle exposure conditions, 6 hrs/day for 3 days in rats 10-12 weeks old

\begin{tabular}{lccccc}
\hline & \multicolumn{3}{c}{ June 2006} & & \multicolumn{2}{c}{ November 2006 } \\
\cline { 2 - 3 } Concentration & Week & Week & & Week & Week \\
& $\mathbf{1}$ & $\mathbf{2}$ & & $\mathbf{1}$ & $\mathbf{2}$ \\
\hline Fine/ultrafine & 392 & 268 & & 320 & 131 \\
Coarse & 268 & 214 & & 298 & 292 \\
\hline
\end{tabular}

chemical and biological composition, two Micro Orifice Uniform Deposit Impactors (MOUDI) collected sizefractionated ambient particulate-matter samples onto Teflon and quartz filters. Particle-mass concentrations were also obtained from the coarse and fine/ ultrafine concentrator filters to verify particle concentration efficiency.

\section{Observations following exposure}

The average concentrations of ambient particles were measured for each inhalation study by week and season (table 1). Although the total mass concentration of particles in the air changed little from week 1 to week 2 , during the summer season the chemical composition of the fine/ultrafine $\left(\mathrm{PM}_{2.5} / \mathrm{PM}_{0.1}\right)$ and coarse $\left(\mathrm{PM}_{10}\right)$ particles varied widely (figs. 1 and 2). Most notable was the variability in nitrate, sulfate, organic material, phosphate and metal content of the particles. Although cations are clearly present in the mixture of ambient particulate matter, they were not measured because the study did not focus on particle acidity. We only measured nitrates and sulfates based on the assumption that they are likely to be in the form of their fully neutralized ammonium salts. Previous 


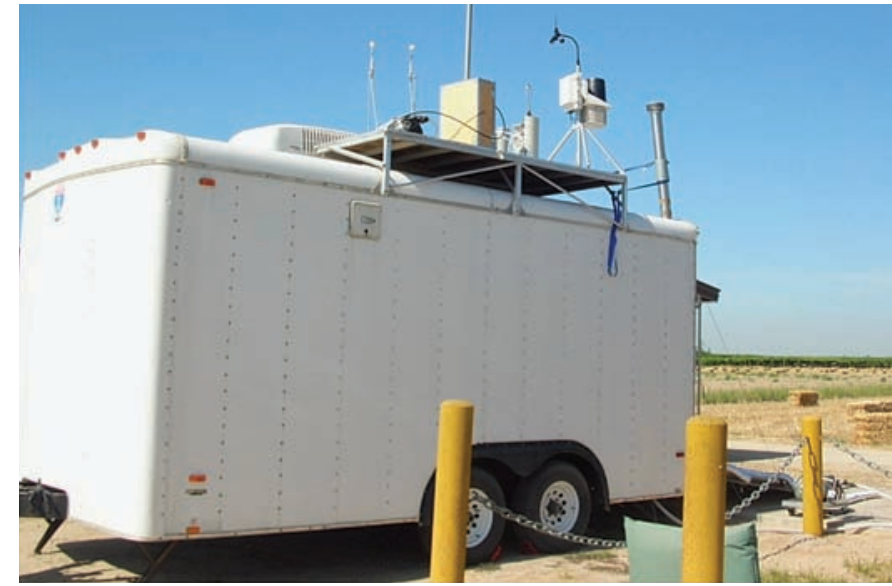

A mobile trailer was used to conduct field air-quality studies at the Kearney Agricultural Research Center in Parlier.

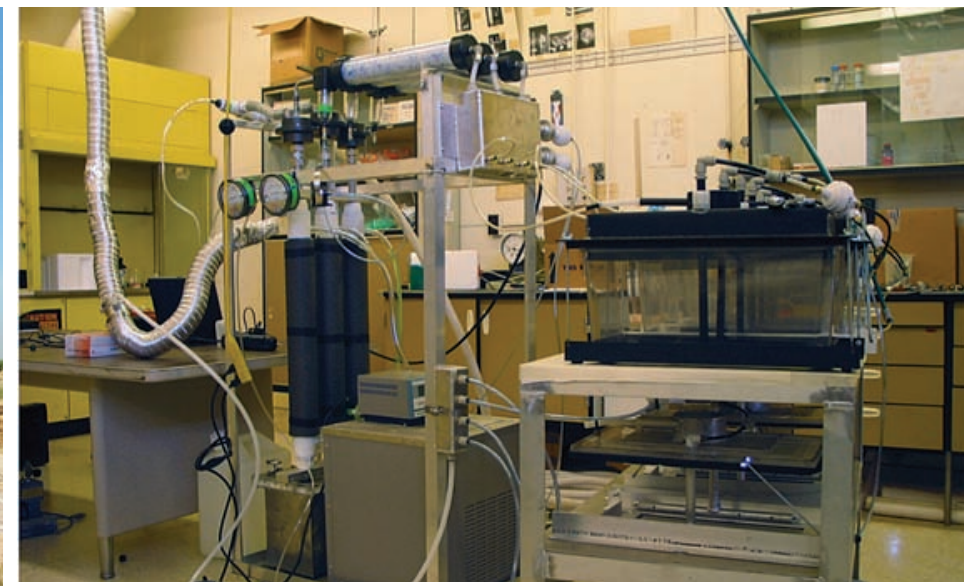

Rats were exposed to airborne particulate matter via an aerosol concentrator (VACES) in inhalation chambers. studies have verified that ammonia is present in excess amounts within the San Joaquin Valley and that ammonium ion is the dominant cation in the $\mathrm{PM}_{2.5}$ size range (Herner et al. 2005, 2006).

Following 3 days of exposure to concentrated ambient particles (6 hours per day), the animals were examined for evidence of changes in the lungs, systemic circulation and central nervous system. Assays were designed to measure cell injury, inflammation or mediators involved in inflammation and altered metabolic function. These assays included the examination of immune cells, tissue pathology and gene expression. Bronchoalveolar lavage (a method of sterile saline instillation) was used to recover cells from the lungs. For experiments to date, no statistically significant increases in the number of lung cells recovered from the rats have been noted, suggesting that there is no active recruitment of immune cells from the blood to the lungs due to inhaled particles.

However, in one experiment where cells were recovered from the lungs by lavage, a significant increase in the proportion of cells with increased permeability or cell membrane leakage (reflecting irreversible cell injury) was observed following exposure to fine/ ultrafine particles, but not to coarse particles (fig. 3). In contrast, some experiments demonstrated a slight, but statistically significant, increase in the total number of neutrophils (white blood cells involved in inflammation and immune responses of the body) recovered by bronchoalveolar lavage after exposure to coarse particles (data not shown). Also, the results of one experiment showed a significant increase in the amount of interleukin $1 ß$ (IL-1ß), a proinflammatory cytokine, in the lungs of rats exposed to fine/ultrafine particles compared with rats exposed to coarse particles or in the control. Together, these findings suggest that short-term exposure to concentrated ambient particles can be associated with occasional subtle, but significant, particle effects.

The examination of blood samples from each experimental group of animals failed to demonstrate significant changes in markers of oxidative stress, metabolic alteration or proinflammatory cytokines. However, one experiment resulted in a particularly intriguing finding: a significant increase in gene expression for interleukin-6 (IL-6), a proinflammatory cytokine, in the brains of animals exposed to fine/ ultrafine particles compared to animals

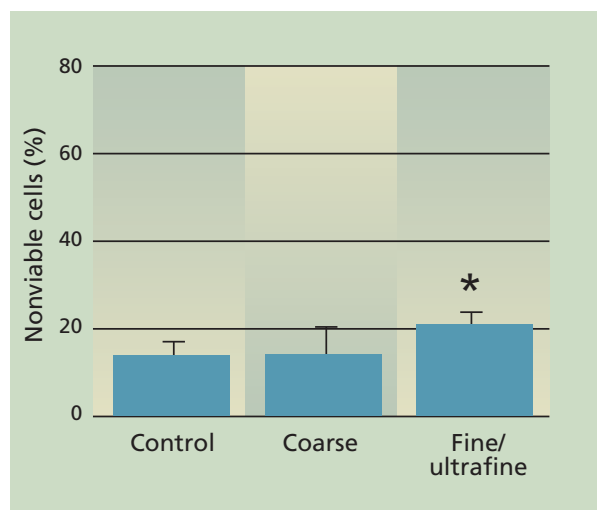

Fig. 3. Proportion of nonviable cells recovered from rat lungs following exposure to concentrated ambient particles in the San Joaquin Valley. Asterisk notes significant change from filtered air control $(P<0.05)$. exposed to coarse particles (fig. 4). This observation suggests that inhaled particles may have an effect on nonrespiratory organ systems such as the central nervous system, and we plan to study this area further.

\section{Future research}

We have observed seasonal variability in particle mass and composition along with small, significant changes in some markers of inflammation and cell viability. This type of field study, which characterizes ambient particulate-matter mixtures found in agricultural regions and determines health outcomes in animal inhalation models, helps provide new insights into how particulate matter affects agricultural workers and residents living in the San Joaquin Valley. This was a relatively short study (3day exposure), and in the future we

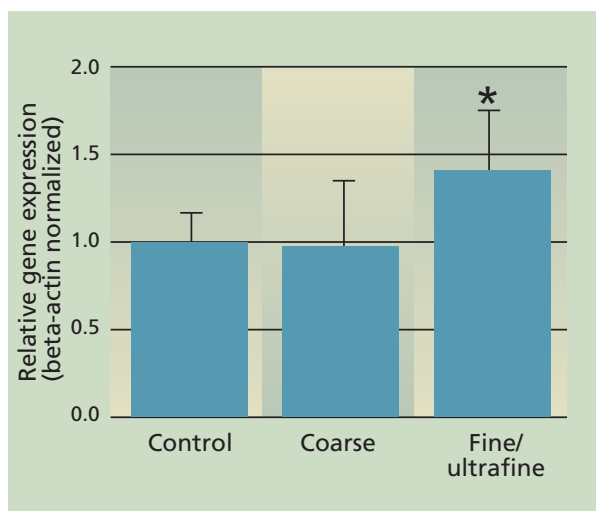

Fig. 4. IL-6 mRNA expression in the rat central nervous system following short-term repeated exposure to concentrated ambient particles. Asterisk notes significant change from control $(P<0.05)$. 
plan to conduct longer exposures to more closely mimic the long-term particulate-matter concentrations to which agricultural workers and residents are exposed. We will continue to focus on seasonal differences in fine and coarse particle composition and whether there are particular physical and chemical properties of particulate matter (such as size or composition) that are especially relevant to adverse health effects. The ultimate goal of these inhalation studies is to provide information to improve the health of people working and living in the San Joaquin Valley.

M.A. Ngo is Postdoctoral Fellow, Center for Health and the Environment (CHE), UC Davis; K.E. Pinkerton is Director, CHE, UC Davis; S. Freeland is Manager, Western Center for Agricultural Health and Safety (WCAHS), UC Davis; M. Geller is Postdoctoral Fellow, Department of Civil and Environmental Engineering, University of Southern California (USC); W. Ham is Graduate Student Researcher, Department of Civil and Environmental Engineering, UC Davis; S. Cliff is Project Scientist, San Joaquin Valley Aerosol Health Effects Research Center, UC Davis; L.E. Hopkins is Graduate Student Researcher, CHE, UC Davis ; M.J. Kleeman is Professor, Department of Civil and Environmental Engineering, UC Davis; U.P. Kodavanti is Senior Scientist, U.S. Environmental Protection Agency; E. Meharg is Graduate Student Researcher, L. Plummer is Graduate Student Researcher, and J.J. Recendez is Staff Research Associate, CHE, UC Davis; M.B. Schenker is Professor, WCAHS, UC Davis; C. Sioutas is Professor, Department of Civil and Environmental Engineering, USC; S. Smiley-Jewell is Principal Editor, and C. Haas is Student Assistant, CHE, UC Davis; J. Gutstein is Director, Public Service Research Program, John Muir Institute of the Environment, UC Davis; and A.S. Wexler is Professor, Department of Mechanical and Aeronautical Engineering, UC Davis.

We thank Fred Swanson, Director of the UC Kearney Agricultural Research Center in Parlier and the Center staff for their assistance and access to laboratory space to conduct these on-site experiments. We also thank the California Department of Pesticide Regulation for collaboration. This research was funded in part by a grant from the National Institute of Occupational Safety and Health (U07/CCU906162) and the U.S. Environmental Protection Agency (RD-832414 and R826246) to UC Davis. The research presented here has not been subject to the EPA's required peer and policy review. It does not necessarily reflect the views of the agency, and no official endorsement should be inferred.

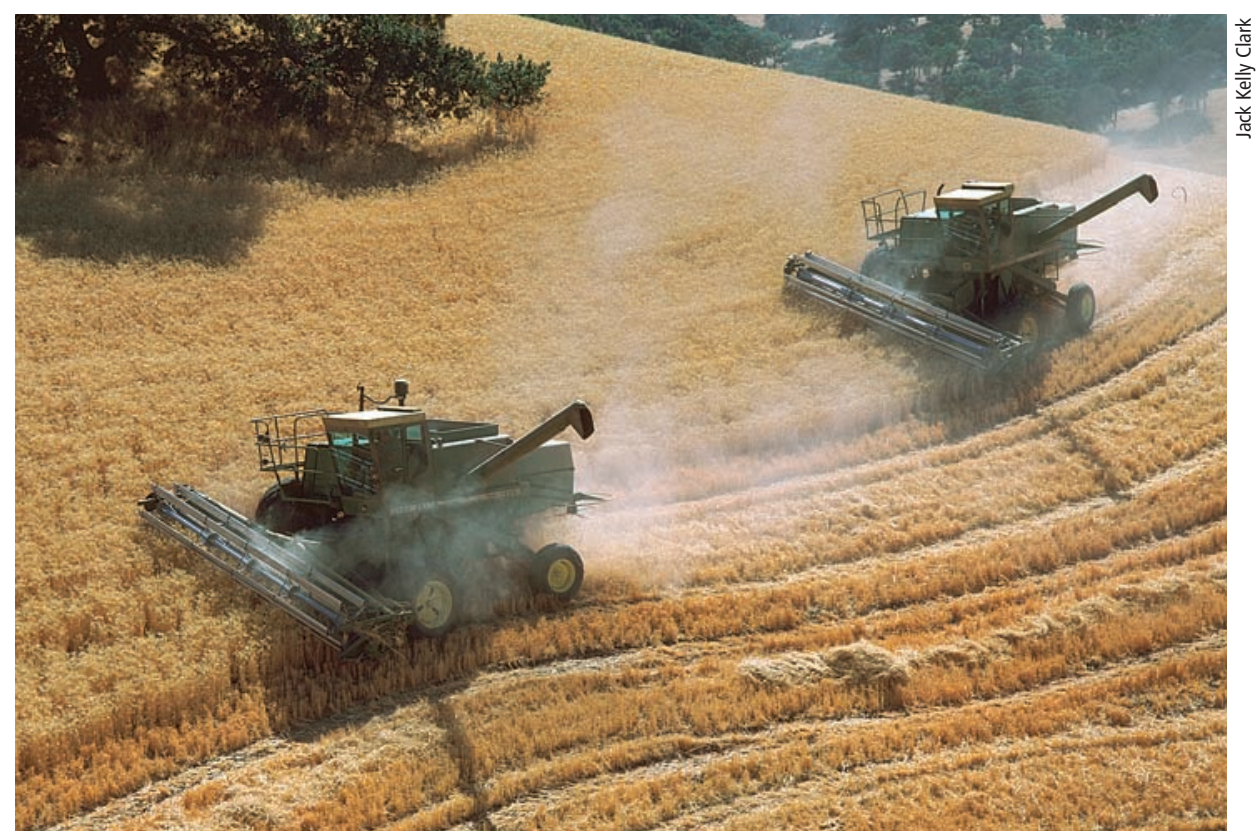

Particulate matter has been linked to adverse health effects including cardiovascular illness and asthma. Agricultural operations, such as wheat harvesting in Yolo County, above, can generate dust.

\section{References}

[CDFA] California Department of Food and Agriculture. 2009. An overview of California agricultural production statistics. Sacramento, CA. http://www. cdfa.ca.gov/statistics.

Chow JC, Watson JG, Lowenthal DH, et al. 1993. $\mathrm{PM}(10)$ and $\mathrm{PM}(2.5)$ compositions in California San Joaquin Valley. Aerosol Sci Technol 18(2):105-28.

Chow JC, Watson JG, Lowenthal DH, et al. 1999. Temporal variations of $\mathrm{PM}_{2.5}, \mathrm{PM}_{10}$, and gaseous precursors during the 1995 integrated monitoring study in central California. J Air Waste Manag Assoc 49:16-24.

Davidson C, Phalen R, Solomon P. 2005. Airborne particulate matter and human health: A review. Aerosol Sci Technol 38(8):737-49.

Englert N. 2004. Fine particles and human health a review of epidemiological studies. Toxicol Lett 149(1-3):235-42.

Ghio AJ, Stonehuerner J, Dailey LA, et al. 1999. Metals associated with both the water-soluble and insoluble fractions of an ambient air pollution particle catalyze an oxidative stress. Inhal Toxicol 11(1):37-49.

Herner JD, Aw J, Gao O, et al. 2005. Size and composition distribution of airborne particulate matter in northern California: I - particulate mass, carbon, and water-soluble ions. J Air Waste Manag Assoc 55(1):30-51.

Herner JD, Aw J, Gao O, et al. 2006. Dominant mechanisms that shape the airborne particle size and composition distribution in central California. Aerosol Sci Technol 40:827-44.

Kim S, Jaques PA, Chang M, et al. 2001. Versatile aerosol concentration enrichment system (VACES) for simultaneous in vivo and in vitro evaluation of toxic effects of ultrafine, fine and coarse ambient particles -
Part I: Development and laboratory characterization. J Aerosol Sci 32(11):1281-97.

Ostro B, Broadwin R, Green S, et al. 2006. Fine particulate air pollution and mortality in nine California counties: Results from CALFINE. Env Health Perspect 114(1):29-33

Peters A, Wichmann HE, Tuch T, et al. 1997. Respiratory effects are associated with the number of ultrafine particles. Am J Respir Crit Care Med 155(4):1376-83

Pope 3rd CA. 2007. Mortality effects of longer term exposures to fine particulate air pollution: Review of recent epidemiological evidence. Inhal Toxicol 19 Suppl 1:33-8.

Pope 3rd CA, Dockery DW. 2006. Health effects of fine particulate air pollution: Lines that connect. J Air Waste Manag Assoc 56(6):709-42.

Samet JM, Dominici F, Curriero FC, et al. 2000. Fine particulate air pollution and mortality in 20 U.S. cities, 1987-1994. N Engl J Med 343(24):1742-9.

Sheppard L, Levy D, Norris G, et al. 1999. Effects of ambient air pollution on nonelderly asthma hospital admissions in Seattle, Washington, 1987-1994. Epidemiology 10(1):23-30.

Smith KR, Kim S, Recendez JJ, et al. 2003. Airborne particles of the California Central Valley alter the lungs of healthy adult rats. Env Health Perspect 111(7):902-8; discussion A408-9.

State of California. 2007. Population Projections for California and Its Counties, 2000-2050. Department of Finance. http://www.dof.ca.gov/html/ DEMOGRAP/ReportsPapers/Projections/P1/P1.php.

Velasco P. 2005. Characterization of Ambient PM10 and $\mathrm{PM}_{2.5}$ in California. California Environmental Protection Agency Air Resources Board. Sacramento, CA. 